\title{
A Prospective Study on Risk Factors and Drug Utilization Review Based on Clinical Profiles in Diabetic Emergency in a Tertiary Care Hospital
}

\author{
Avvari Sanjeeva Kumar ${ }^{1 *}$, Amatinthala Ashok², Maddika Anusha ${ }^{2}$, Aeman Shafeen², Reddypogu Jona \\ Methusala ${ }^{1}$
}

${ }^{1}$ Department of Pharmacology, Dr. K. V. Subba Reddy Institute of Pharmacy, Kurnool, Andhra Pradesh, INDIA.

${ }^{2}$ Department of Pharmacy Practice, Dr. K. V. Subba Reddy Institute of Pharmacy, Kurnool, Andhra Pradesh, INDIA.

\begin{abstract}
Background: Diabetic Ketoacidosis (DKA) is a triad of Diabetes, ketosis and metabolic acidosis. Aim: To estimate the risk factors and drug utilization review based on clinical profiles in diabetic emergency (DKA) in a tertiary care hospital prospectively. Objectives: To determine the demographic characters (Gender, Age and Sex), type of diabetics, clinical manifestations, precipitating factors, comorbidities, biochemical parameters and therapeutic drug monitoring parameters like Drug interactions, ADR's, untreated indications. Methods: A Prospective crosssectional study was conducted on 50 patients in both male and female general medicine units at Government General Hospital, Kurnool. The patients were selected based on the inclusion criteria. Newly diagnosed diabetic patients with Diabetic Ketoacidosis and past history of hospitalization due to occurrence of Diabetic Ketoacidosis were also included in the study. Results: Diabetic Ketoacidosis was seen in both types I and type II diabetes. Among the study population female patients were higher in number. Presentation of Diabetic ketoacidosis was higher among the type II diabetes. Diabetic Ketoacidosis among adults was more common amongst the patients in age groups of 30-40 and 50-60 years of age. Nausea, vomiting and shortness of breath were the most common presenting complaints. Most common precipitating factors include Drug Incompliance and Infection. Random blood sugar levels were more than $300 \mathrm{mg} / \mathrm{dL}$ in majority of patients. The treatment had seven adverse drug reactions and nine untreated indications in the study. Conclusion: Most common precipitating factors include Drug Incompliance (32\%) and Infection.
\end{abstract}

Key words: Diabetes, Diabetic Ketoacidosis, Drug utilization review, Drug incompliance, Precipitating Factors and Therapeutic drug monitoring.

\section{INTRODUCTION}

Diabetic Ketoacidosis (DKA) results from absolute or relative deficiency of circulating insulin and the combined effects of increased levels of the counter regulatory hormones: glucagon, catecholamines, growth hormone and cortisol. Absolute insulin deficiency presents in previously undiagnosed type 1 diabetes mellitus and patients on treatment who deliberately, inadequately or do not take insulin, especially the long-acting component of a basal-bolus regimen. Patients who are all on insulin pump can also develop Diabetic Ketoacidosis when insulin delivery fails for any reason.

Relative insulin deficiency can occur when the concentrations of counter regulatory hormones by increase in response to stress in such conditions like trauma, sepsis, or diarrhoea and vomiting. ${ }^{1}$

In condition where there is low serum insulin and high counter regulatory hormones. There occurs an increased catabolic state with increased glucose production by the liver and kidney through glycogenolysis and gluconeogenesis. Impairment in peripheral glucose utilization results in hyperglycemia, increased lipolysis, hyperosmolality and ketogenesis. ${ }^{1}$ This causes ketonemia and metabolic acidosis. If hyperglycemia increases more than renal threshold (approximately 10 $\mathrm{mmol} / \mathrm{L}[180 \mathrm{mg} / \mathrm{dL}]$ it results in osmotic diuresis and obligatory loss of electrolytes,
DOI: 10.5530/ijopp.13.1.4

Address for correspondence: Dr. Sanjeeva Kumar, Department of Pharmacology, Dr. K. V. Subba Reddy Institute of Pharmacy, Kurnool, Andhra Pradesh, INDIA.

Phone no: +91 9885262871 Email Id: avvarisanjeev@gmail. com

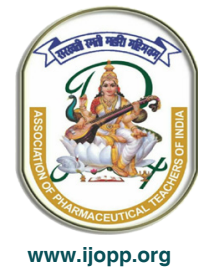


causing dehydration which is aggravated by vomiting. These changes also stimulate further stress hormone production. $^{2}$

This leads to worsening hyperglycemia, more severe insulin resistance and hyperketonemia. If this progression is not controlled with exogenous insulin, fluid and electrolyte therapy, it will cause fatal dehydration and metabolic acidosis. Ketoacidosis is also aggravated by lactic acidosis caused from poor tissue perfusion and sepsis. $^{3}$

\section{MATERIALS AND METHODS}

\section{Place of Study}

Government General Hospital, Kurnool, a 1000 bed teaching hospital.

\section{Period of Study}

The study period was Six months i.e., from August 2018 to January 2019.

\section{Study Population}

50 patients fit into inclusion criteria from both female and male General Medicine departments.

\section{Study Design}

A Prospective cross-sectional study

\section{Inclusion Criteria}

The patient should be previously diagnosed diabetic or de novo diabetic and pediatrics are excluded.

\section{Biochemical Inclusion criteria}

The patient should have high glycemic levels.

The patient should be positive for ketone bodies in the blood.

Acidic $\mathrm{PH}$ values in a patient which are estimated by the physician.

\section{IRB Approval}

The research protocol was duly approved by IRB of Dr. K. V. Subba Reddy Institute of Pharmacy vide approval number KVSP/IRB 2018-2019/Pharm.D/PROJ/001.

\section{Method of Study}

The study begins with the selection of the patients based on the inclusion criteria followed by the collection of all the baseline parameters of the patient's demographic details, medical history, past allergies, personal history, family history, laboratory data and present treatment and all the data of the data of the subjects are collected by using the patient proforma.

\section{RESULTS}

\section{Age Distribution}

A total of 50 patients were analyzed for a period of 6 months.

Table 1 furnishes the details of patient's age distribution. Among 50 patients Diabetic Ketoacidosis (DKA) was more common among the age group of 30-40 and 50-60 years of age as shown in Figure 1. The average age was found to be 36.98 ( $\mathrm{SD} \pm 16.48$ ) years.

\section{Gender Distribution}

Table 2 furnishes the details of patient's gender distribution. Among 50 Patients the distribution of gender is as follows i.e., Females are 27(54\%) and Males are $23(46 \%)$ as shown in Figure 2.

\section{Distribution of Diabetic Population}

Table 3 furnishes the details of distribution of diabetic population. Among 50 Patients, 21 (42\%) were type - I and $29(58 \%)$ were types - II patients as shown in Figure 3.

\section{De novo Diabetic Population}

Table 4 furnishes the details of de novo diabetic population. Among the de novo presentations in 13 patients, 3 (24\%) patients were type - I and $10(76 \%)$ patients were types II de novo diabetics as shown in Figure 4. Average de novo diabetics among 13 patients were 6.5 SD \pm 4.94 .

\section{Precipitating Factors in DKA Patients}

Table 5 furnishes the details of precipitating factors in DKA patients. Among 50 patients, the most common precipitating factor was Drug incompliance $16(32 \%)$ and followed by Urinary tract infections $12(24 \%)$, pancreatitis $3(6 \%)$, Gastroenteritis 3(6\%), Acute febrile illness 2(4\%), sepsis $2(4 \%)$, Diabetic foot ulcer $1(2 \%)$, starvation $1(2 \%)$. Among 50 patients first presentations of DKA were 13 $(26 \%)$ and unknown causes for Diabetic Ketoacidosis (DKA) were 8(16\%) as shown in Figure 5.

\section{Clinical Manifestations}

Table 6 furnishes the details of clinical manifestations in DKA. Among the 50 patients, 34(68\%) had nausea and vomiting as chief presenting symptoms. $33(66 \%)$ had 
Shortness of breath, 24(48\%) had the fever, 23(46\%) had abdominal pain, Kussmaul respiration 12(24\%) and Altered sensorium $5(10 \%)$ as shown in Figure 6.

\section{Glycemic Levels}

Table 7 furnishes the details of glycemic levels. Among the 50 patients $15(30 \%)$ patients had Random blood sugar values of about $200-300 \mathrm{mg} / \mathrm{dL}$ and $11(22 \%)$ of patients had $300-400 \mathrm{mg} / \mathrm{dL}, 9(18 \%)$ of patients had $400-500 \mathrm{mg} / \mathrm{dL}, 11(22 \%)$ had $500-600 \mathrm{mg} / \mathrm{dL}$ and $2(4 \%)$ had $600-700 \mathrm{mg} / \mathrm{dL}$ of Random blood sugar as shown in Figure 7. Average RBS value among 50 patients was found to be $383 \mathrm{mg} / \mathrm{dL} \mathrm{SD} \pm 130.6989$.

\section{Distribution of Co-morbidities}

Table 8 furnishes the details of distribution of comorbidities. Among previous co-morbidities 15 (30\%) of patients had hypertension, $3(6 \%)$ had pancreatitis, 1 $(2 \%)$ had AKI, 1(2\%) had CKD, 1(2\%) had 1(2\%) had Diabetic foot ulcer, $1(2 \%)$ had Hypothyroidism as shown in Figure 8. The average number of patients having comorbidities was found to be $3.66 \mathrm{SD} \pm 5.609$.

\section{Ketone Index in DKA Patients}

Table 9 furnishes the details of ketone index in diabetic ketoacidosis patients. Among 50 patients, 11 (22\%) of patients were found with Small, 17(34\%) of patients with Moderate and 22 (44\%) of patients with Large levels of ketone bodies in urine as shown in Figure 9.

\section{Therapeutic Drug Monitoring}

Table 10 furnishes the details of therapeutic drug monitoring (occurrence of adverse drug reactions and drug interactions) in diabetic ketoacidosis patients. Therapeutic Drug Monitoring in 50 patients reveals that the treatment has $9(18 \%)$ Untreated indications, $7(14 \%)$ Adverse Drug Reactions, 1(2\%) Drug interactions as shown in Figure 10. The average number of patients having therapeutic drug errors was found to be 5.6 (SD $\pm 4.16)$.

\section{Untreated Indications}

Table 11 depicts the number of untreated indicatons in patients. Among 50 patients treatment, $9(18 \%)$ untreated indications were found as shown in Figure 11.

\section{Adverse Drug Reactions}

Table 12 depicts the number of adverse drug reactions in patients. It depicts the total of 7(14\%) ADR's occurred among 50 patients as shown in Figure 11.

\begin{tabular}{|c|c|c|c|}
\hline S. No. & Age & No. of Patients & Percentage (\%) \\
\hline 1 & $10-20$ & 11 & 22 \\
\hline 2 & $21-30$ & 7 & 14 \\
\hline 3 & $31-40$ & 12 & 24 \\
\hline 4 & $41-50$ & 6 & 12 \\
\hline 5 & $51-60$ & 12 & 24 \\
\hline 6 & $61-70$ & 2 & 4 \\
\hline
\end{tabular}

Mean $\pm S D{ }_{3} 6.98 \pm 16.48$

Table 2: Gender Distribution $(n=50)$.

\begin{tabular}{cccc} 
S. No. & Gender & No. of Patients & Percentage (\%) \\
\hline 1 & Male & 23 & 46 \\
2 & Female & 27 & 54 \\
\hline
\end{tabular}

Table 3: Distribution of Diabetic population ( $n=50)$.

\begin{tabular}{cccc}
$\begin{array}{c}\text { S. } \\
\text { No. }\end{array}$ & $\begin{array}{c}\text { Type of } \\
\text { Diabetes }\end{array}$ & No. of Patients & $\begin{array}{c}\text { Percentage } \\
\text { (\%) }\end{array}$ \\
\hline 1 & Type - I & 21 & 42 \\
2 & Type - II & 29 & 58 \\
\hline
\end{tabular}

\begin{tabular}{cccc|} 
Table 4: De novo diabetes $(n=\mathbf{1 3})$. & \\
S. No. & $\begin{array}{c}\text { Type of de novo } \\
\text { Diabetes }\end{array}$ & $\begin{array}{c}\text { No. of } \\
\text { Patients }\end{array}$ & $\begin{array}{c}\text { Percentage } \\
\text { (\%) }\end{array}$ \\
\hline 1 & Type - I & 3 & 24 \\
2 & Type - II & 10 & 76 \\
\hline
\end{tabular}

Mean \pm SD $6.5 \pm 4.94$

\section{Table 5: Precipitating Factors $(n=50)$}

\begin{tabular}{cccc}
$\begin{array}{c}\text { S. } \\
\text { No. }\end{array}$ & $\begin{array}{c}\text { Precipitating } \\
\text { Factors }\end{array}$ & $\begin{array}{c}\text { No. of } \\
\text { Cases }\end{array}$ & $\begin{array}{c}\text { Percentage } \\
(\%)\end{array}$ \\
\hline 1 & Drug Incompliance & 16 & 32 \\
2 & Urinary Tract & 12 & 24 \\
Infections & & \\
3 & Sepsis & 2 & 4 \\
4 & Diabetic Foot Ulcer & 1 & 2 \\
5 & Gastroenteritis & 3 & 6 \\
6 & Acute Febrile illness & 2 & 4 \\
7 & Pancreatitis & 3 & 6 \\
8 & Starvation & 1 & 2 \\
9 & First Presentation & 13 & 26 \\
10 & Unknown & 8 & 16 \\
\hline
\end{tabular}

\section{Type of ADR}

Table 13 depicts the type of adverse drug reactions as shown in Figure 12. During the treatment of 50 DKA patients, $7(14 \%)$ were found. Out of which $4(8 \%)$ were Indian Journal of Pharmacy Practice, Vol 13, Issue 1, Jan-Mar, 2020 


\begin{tabular}{|c|c|c|c|}
\hline $\begin{array}{l}\text { S. } \\
\text { No. }\end{array}$ & $\begin{array}{c}\text { Clinical } \\
\text { Manifestations }\end{array}$ & $\begin{array}{l}\text { No. of. } \\
\text { Cases }\end{array}$ & $\begin{array}{c}\text { Percentage } \\
(\%)\end{array}$ \\
\hline 1 & Nausea/Vomiting & 34 & 68 \\
\hline 2 & Abdominal Pain & 23 & 46 \\
\hline 3 & Shortness of Breath & 33 & 66 \\
\hline 4 & Fever & 24 & 42 \\
\hline 5 & $\begin{array}{l}\text { Kussmaul } \\
\text { Respiration }\end{array}$ & 12 & 24 \\
\hline 6 & Altered Sensorium & 5 & 10 \\
\hline 7 & Lethargy & 36 & 72 \\
\hline 8 & $\begin{array}{l}\text { Constitutional } \\
\text { Symptoms }\end{array}$ & 29 & 58 \\
\hline
\end{tabular}

\section{Table 7: Glycemic Levels $(n=50)$.}

\begin{tabular}{cccc}
$\begin{array}{c}\text { S. } \\
\text { No. }\end{array}$ & $\begin{array}{c}\text { Glycemic Range } \\
(\mathbf{m g} / \mathrm{dL})\end{array}$ & $\begin{array}{c}\text { No. of } \\
\text { Patients }\end{array}$ & $\begin{array}{c}\text { Percentage } \\
(\%)\end{array}$ \\
\hline 1 & $100-200$ & 2 & 4 \\
2 & $200-300$ & 15 & 30 \\
3 & $300-400$ & 11 & 22 \\
4 & $400-500$ & 9 & 18 \\
5 & $500-600$ & 11 & 22 \\
6 & $600-700$ & 2 & 4 \\
\hline
\end{tabular}

Mean \pm SD $383 \pm 130.6989$

\begin{tabular}{cccc}
\multicolumn{4}{c}{ Table 8: Co morbidities in DKA Patients $(\boldsymbol{n}=\mathbf{5 0})}$. \\
\hline S. & $\begin{array}{c}\text { Type of Co } \\
\text { morbidity }\end{array}$ & $\begin{array}{c}\text { No. of } \\
\text { Patients }\end{array}$ & $\begin{array}{c}\text { Percentage } \\
\text { (\%) }\end{array}$ \\
\hline 1 & Hypertension & 15 & 30 \\
2 & Acute Kidney Injury & 1 & 2 \\
3 & $\begin{array}{c}\text { Chronic Kidney } \\
\text { Disease }\end{array}$ & 1 & 2 \\
4 & $\begin{array}{c}\text { Pancreatitis } \\
5\end{array}$ & 3 & 6 \\
6 & Diabetic Foot Ulcer & 1 & 2 \\
\hline
\end{tabular}

Mean $\pm S D$ S $3.66 \pm 5.609$

\section{Table 9: Ketone Index $(n=50)$.}

\begin{tabular}{cccc}
$\begin{array}{c}\text { S. } \\
\text { No. }\end{array}$ & Ketone Range & $\begin{array}{c}\text { No. of } \\
\text { Patients }\end{array}$ & $\begin{array}{c}\text { Percentage } \\
\text { (\%) }\end{array}$ \\
\hline 1 & Small & 11 & 22 \\
2 & Moderate & 17 & 34 \\
3 & Large & 22 & 44 \\
\hline
\end{tabular}

Diarrhea, 2(4\%) were Dyspepsia and 1(2\%) were Allergic reaction. Average number of ADR in 50 patients was found to be $2.3(\mathrm{SD} \pm 1.5)$.
Table 10: Therapeutic Drug Monitoring ( $n=50)$.

\begin{tabular}{cccc} 
S. No. & Factor & $\begin{array}{c}\text { No. of } \\
\text { patients }\end{array}$ & Percentage \% \\
\hline 1. & Untreated indications & 9 & 18 \\
2. & Adverse Drug Reactions & 7 & 14 \\
3. & Drug Interactions & 1 & 2 \\
4. & Patient factors & 0 & 0 \\
\hline
\end{tabular}

Mean \pm SD $5.6 \pm 4.16$

Table 11: Untreated indications $(n=50)$.

\begin{tabular}{cccc}
$\begin{array}{c}\text { S. } \\
\text { No. }\end{array}$ & FACTOR & $\begin{array}{c}\text { No. of } \\
\text { patients }\end{array}$ & Percentage $\%$ \\
\hline 1. & Untreated indication & 9 & 18 \\
\hline
\end{tabular}

\section{Table 12: Adverse Drug Reactions ( $n=50$ ).}

\begin{tabular}{cccc}
$\begin{array}{c}\text { S. } \\
\text { No. }\end{array}$ & FACTOR & $\begin{array}{c}\text { No. of } \\
\text { patients }\end{array}$ & $\begin{array}{c}\text { Percentage } \\
\%\end{array}$ \\
\hline 1. & Adverse Drug Reactions & 7 & 14 \\
\hline
\end{tabular}

\begin{tabular}{|c|c|c|c|}
\hline $\begin{array}{l}\text { S. } \\
\text { No }\end{array}$ & TYPE OF ADR & $\begin{array}{c}\text { No. of } \\
\text { patients }\end{array}$ & $\begin{array}{c}\text { Percentage } \\
\%\end{array}$ \\
\hline 1. & Diarrhea & 4 & 8 \\
\hline 2. & Dyspepsia & 2 & 4 \\
\hline 3. & Allergic Reaction & 1 & 2 \\
\hline
\end{tabular}

Mean \pm SD $2.3 \pm 1.5$

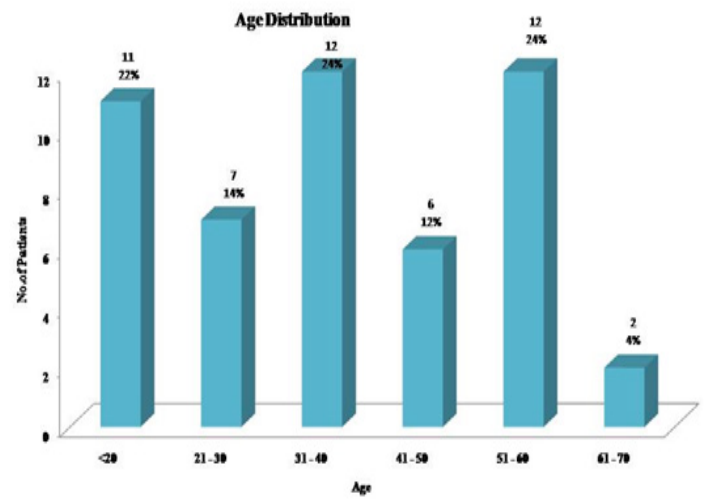

Figure 1: Age Distribution of DKA Patients $(n=50)$.

\section{DISCUSSION}

In Past few decades, DKA was considered to be more prone in Type - I diabetics. But now DKA prevalence of occurring is much into Type $-\mathrm{II}$ diabetics also. ${ }^{4}$ Primary development of DKA is due to absolute or relative lack of circulating insulin and enhanced by counter regulatory hormones like Glucagon, catecholamine's, cortisol and growth hormone. ${ }^{5}$ We conducted a prospective cross sectional study in G.G.H, Kurnool. During a period of six months and collected 50 DKA cases during August 2018 to January 2019. Out of a total of 50 patients, 21 


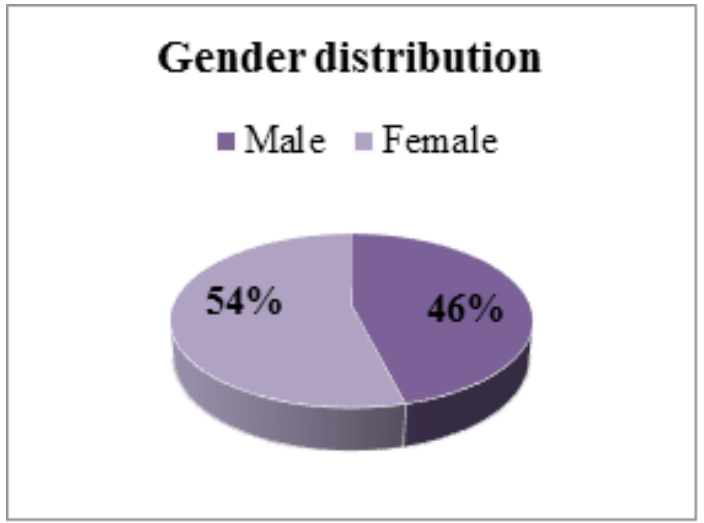

Figure 2: Gender Distribution $(n=50)$.

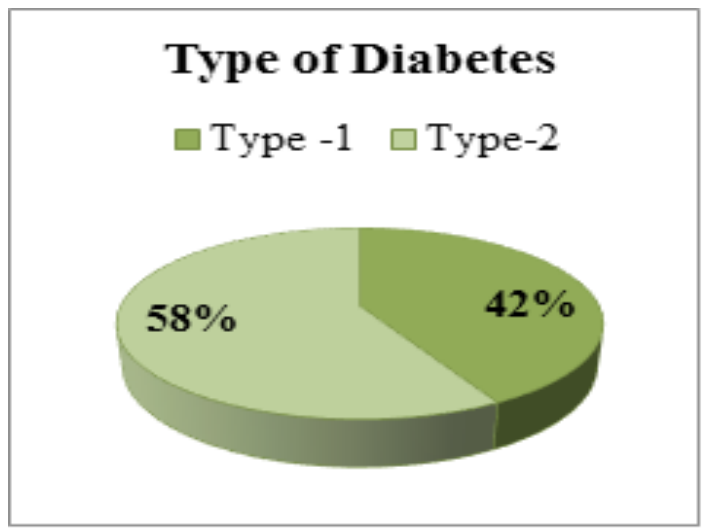

Figure 3: Diabetic Population: $(n=50)$.

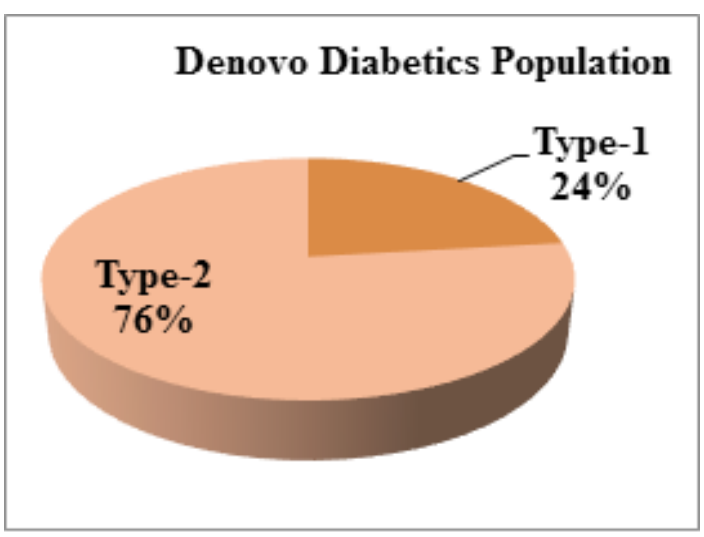

Figure 4: De novo Diabetic Population: $(n=50)$.

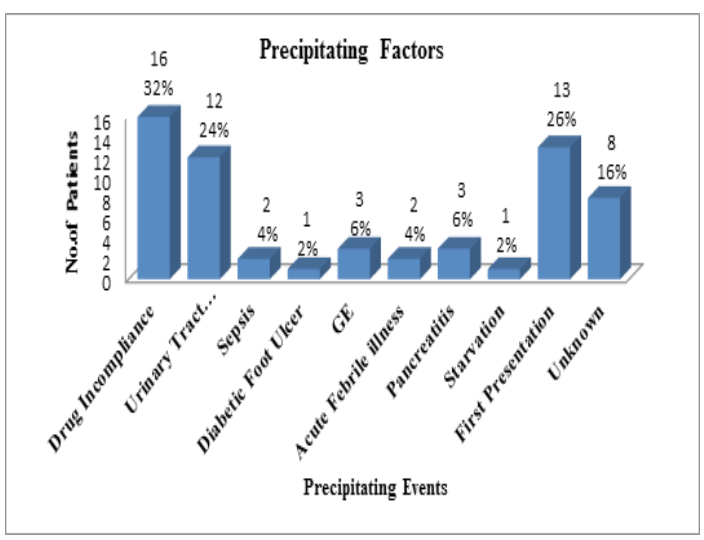

Figure 5: Precipitating Factors: $(n=50)$.

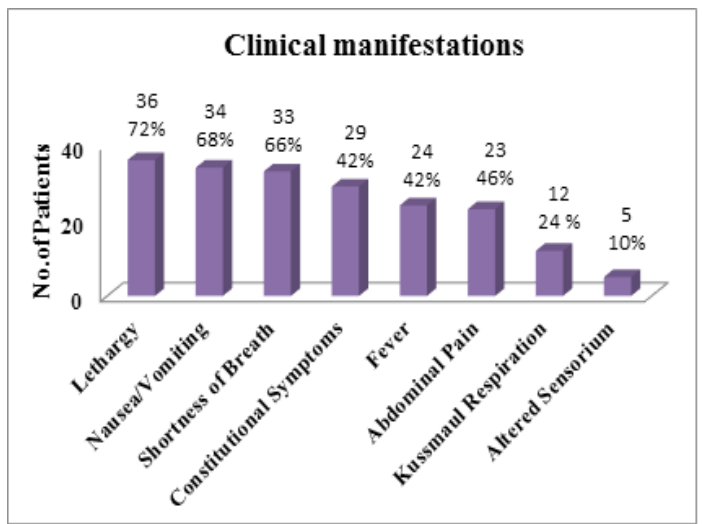

Figure 6: Clinical Manifestations: $(n=50)$.

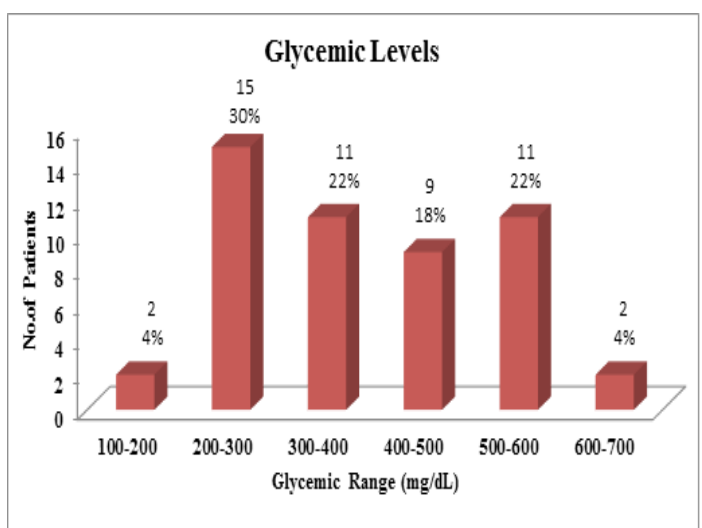

Figure 7: Glycemic Levels ( $n=50)$.

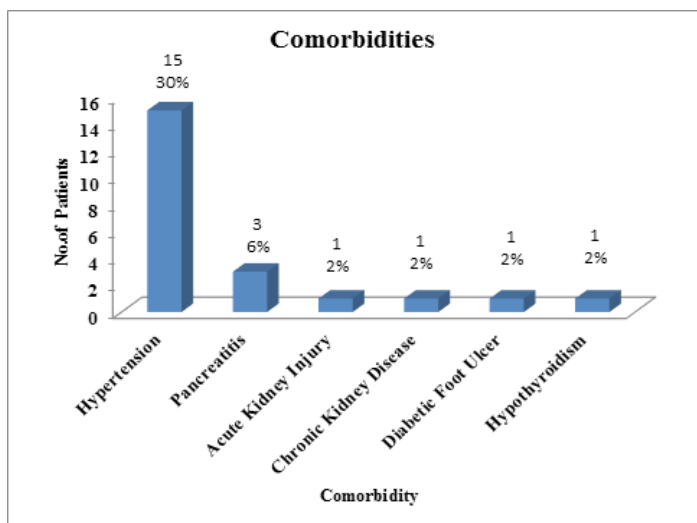

Figure 8: Co morbidities in DKA Patients: $(n=50)$.

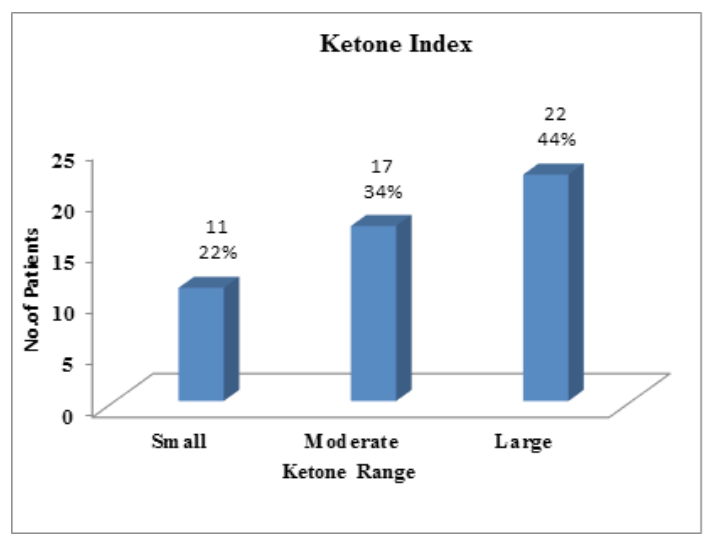

Figure 9: Ketone Index: $(n=50)$. 


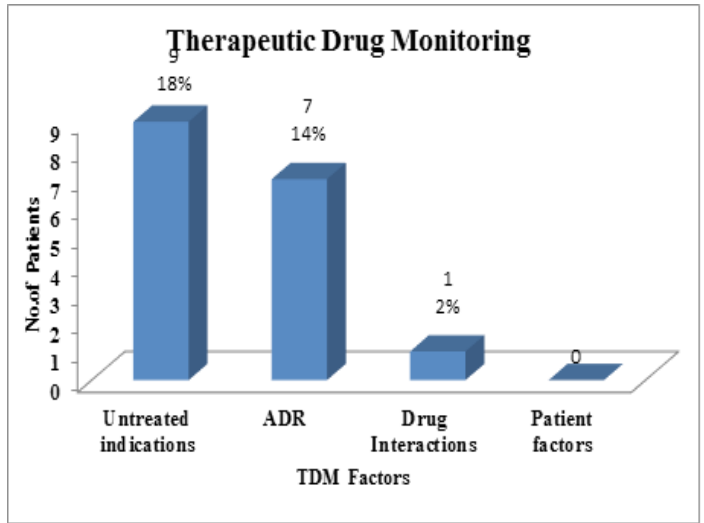

Figure 10: Therapeutic Drug Monitoring $(n=50)$.

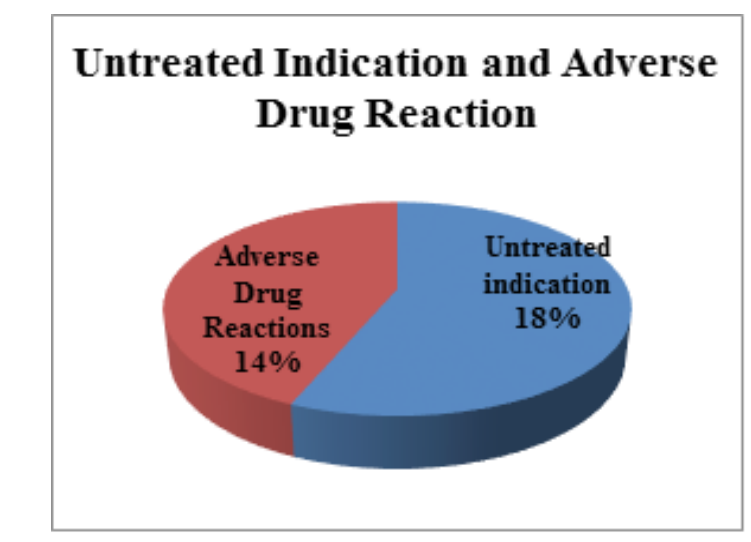

Figure 11: Untreated Indication and Adverse Drug Reaction $(n=50)$.

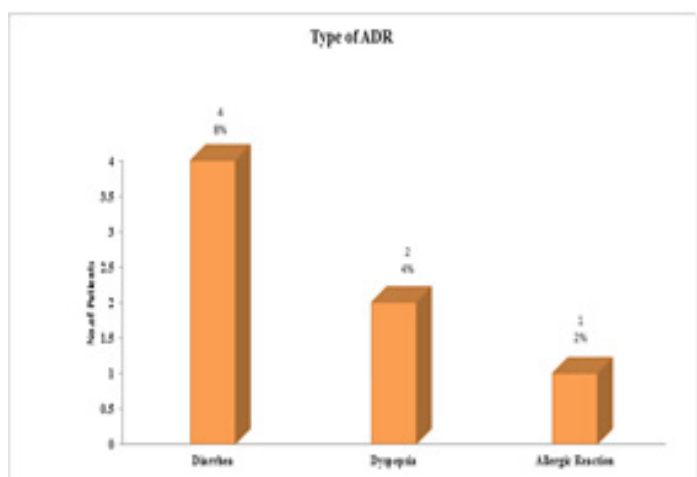

Figure 12: Type of Adverse Drug Reaction $(n=50)$.

$(42 \%)$ of patients are type I Diabetics and $29(58 \%)$ of patients had type II diabetics. Females are more prone to DKA than male population in our study. Majority of the patients $12(24 \%)$ were in the age group of about 30-40 years and 50-60 years of age. The average age was found to be 36.98 years. Most of the DKA patients 34 (68\%) had nausea and vomiting as chief presenting symptoms. The most common precipitating factor was Drug incompliance $16(32 \%)$ and followed by Urinary tract infections 12 (24\%). First presentations of DKA was seen in 13 patients. Among previous comorbidities, in DKA patient's hypertension is about $30 \%$ and is considered as most frequently occurring fatal comorbidity. High Random glycemic levels were noticed in most of the DKA patients. The average Random blood sugar levels are more than $300 \mathrm{mg} / \mathrm{dL}$ in $48(96 \%)$ of patients in majority of patients at time of presentation. $22(44 \%)$ of DKA. ${ }^{6}$

Patients had developed a large range of ketone bodies in urine among 50 patients. Newly diagnosed diabetes were about $13(26 \%)$ patients. Out of thirteen newly detected type I diabetics was $3(23 \%)$ and $10(76.9 \%)$ were type II diabetics. Out of the 50 patients $9(18 \%)$ untreated indications, 7 (14\%) Adverse drug reactions and 1 (2\%) of Drug interactions were found in the treatment. Among 7(14\%) ADR's Diarrhea 4(8\%), Dyspepsia 2(4\%), Allergic Reactions $1(2 \%)$ was found in the treatment. ${ }^{7}$

\section{Role of Clinical Pharmacist in Dka Management}

The ultimate goal of counseling is to provide information directed at encouraging safe and appropriate use of medications, thereby enhancing therapeutic outcomes.

Because of the rapid expansion of available therapeutic agents to treat diabetes, the pharmacist's role in caring for diabetic patients has expanded. The pharmacist can educate the patients about the proper use of medication, screening for drug interactions, explain monitoring devices and make recommendations for ancillary products and services. ${ }^{8,9}$

\section{Essential components of diabetic counseling Counseling regarding lifestyle modifications}

Carbohydrates: $45-60 \mathrm{~g}$ per meal and $10-25 \mathrm{~g}$ per snack, totaling about $135-230 \mathrm{~g}$ per day.

Fat: It is wise to restrict saturated fats and to substitute them with unsaturated fats

Fiber: 25 to $50 \mathrm{~g}$ daily.

\section{CONCLUSION}

From the above study, it was concluded that DKA was seen in both types I and type II diabetes. Among the study population female patients (54\%) were high in number. Presentation of Diabetic ketoacidosis (DKA) was high among the type II diabetes (58\%). DKA among adults was more common among patients in the age group of $30-40(24 \%)$ and $50-60(24 \%)$ years of age. Nausea/ vomiting $(68 \%)$ and shortness of breath $(66 \%)$ were the most common presenting complaints. Most common precipitating factors include Drug Incompliance (32\%) and Infection. Random blood sugar levels are 200-300 
$\mathrm{mg} / \mathrm{dL}(30 \%)$ in the majority of patients at the time of presentation. Hypertension $(30 \%)$ is the major comorbidity among the patients. Many of these cases can be prevented with proper education and effective communication. All patients' treatment was evaluated with regards to Therapeutic Drug Monitoring and concluded that the treatment has Seven Adverse drug reactions $(14 \%)$ and nine untreated indications $(18 \%)$ in the study population.

\section{ACKNOWLEDGEMENT}

It is our immense pleasure to express our heartfelt gratitude and sincere thanks to Dr. K. Narasimhulu M.D. (General Medicine), DTCD, Professor and Head, Department of General Medicine, GGH, Kurnool for his supervision, guidance and support during the study.

We take this opportunity to acknowledge the management, principal, faculty and non-teaching staff of Dr. K.V. Subba Reddy Institute of Pharmacy, Kurnool for providing necessary facilities and timely help to complete our work.

\section{CONFLICT OF INTEREST}

The authors declare no conflict of interest.

\section{ABBREVIATIONS}

ADR: Adverse Drug Reaction, AKI: Acute Kidney Injury; CKD: Chronic Kidney Disease; DKA: Diabetic Ketoacidosis; RBS: Random Blood Sugar.

\section{SUMMARY}

- Among diabetic population type - II diabetics were more prone to Diabetic ketoacidosis.

- The most common Precipitating factor was Drug incompliance and infection.

- Hypertension was the major Comorbidity among the patients.

- Seven ADRs and nine untreated indications were identified in this study.

\section{REFERENCES}

1. Koda-Kimble MA. Koda-Kimble and Young's applied therapeutics: The clinical use of drugs. Lippincott Williams and Wilkins. 2012.

2. Ramin A, Omar A. Nelson text book of pediatrics $20^{\text {th }}$ edition. 2015

3. Kitabchi AE, Umpierrez GE, Fisher JN, Murphy MB, Stentz FB. Thirty years of personal experience in hyperglycemic crises: Diabetic ketoacidosis and hyperglycemic hyperosmolar state. The Journal of Clinical Endocrinology and Metabolism. 2008;93(5):1541-52.

4. American Diabetes Association. Diagnosis and classification of diabetes mellitus. Diabetes Care. 2010;33(Supplement 1):S62-9.

5. Chaudhary R, Singh R, Nigam P. Original research article diabetic ketoacidosisprospective study of clinical profile and outcome in a tertiary care hospital. Adolescence. 2016;10:11.

6. Sonwani S, et al. A Prospective Study of Risk Factors, Clinical Profile and Out Come in Patients of Diabetic Ketoacidosis in Type-II Diabetes Patients. Indian Journal of Contemporary Medical Research. 2018;5(4):D21-4.

7. Siva S, John SM, Roshan M. Drug Utilization Evaluation of HMG-COA Reductase Inhibitors in a Tertiary Care Teaching Hospital. Indian Journal of Pharmacy Practice. 2017;10(4):251-9.

8. Rathinavelu M, Satyagama S, Reddy R, Reddy YP. Drug use evaluation of antimicrobials in healthcare resource limited settings of India. Indian Journal of Pharmacy Practice. 2015;8(4):191.

9. Reddy KS. A Study on Role of Clinical Pharmacist in Identification and Prevention of Medication Errors at a Teritiary Care Hospital. Indian Journal of Pharmacy Practice. 2018;11(4):199. 